\title{
SCLERODERMA OVERLAP SYNDROME: A CASE REPORT
}

Diwakar K. Singh ${ }^{1}$, Nataraju H. V²

\section{HOW TO CITE THIS ARTICLE:}

Diwakar K. Singh, Nataraju H. V. "Scleroderma Overlap Syndrome: A Case Report". Journal of Evolution of Medical and Dental Sciences 2014; Vol. 3, Issue 23, June 09; Page: 6277-6281,

DOI: $10.14260 /$ jemds/2014/2735

ABSTRACT: Overlap syndrome is a condition in which the patient presents with features of two or more diseases. These rheumatic conditions can co-exist in various combinations and are not rare, as myopathy or myositis co-exist in scleroderma in up to $3 \%$ of scleroderma patients. ${ }^{1}$ Here we present a case of 49 years old patient of overlap syndrome (Scleroderma (LcSS)/Myositis (Dermatomyositis). KEYWORDS: Overlap syndrome, scleroderma, dermatomyositis, autoimmune.

INTRODUCTION: As many as 25 percent of rheumatic disease patients with systemic symptoms cannot be definitively diagnosed.(2,3) These patients have been considered to have diffuse or undifferentiated connective tissue diseases (UCTD).(4,5) Other patients with rheumatic diseases have systemic features that overlap two or more specific entities and also cannot be definitively diagnosed, these are said to have "Overlap Syndromes". ${ }^{6}$

Scleroderma is an autoimmune connective tissue disease that causes fibrosis and vascular abnormalities. Some patients with scleroderma can have other autoimmune conditions like rheumatoid arthritis, SLE or inflammatory myopathies such as dermatomyositis or mixed connective tissue disorders.

CASE PRESENTATION: A 49 years lady presented with pain and weakness of both the upper and lower limbs since 8 months. Weakness was in the form of difficulty in getting up from squatting position or climbing stairs and inability to raise the hands above the head level or comb her hair.

The weakness was progressive and at the time of presentation she was bedridden since 15 days. She was able to walk only with the support of two people to carry out the day to day activities. There was history of severe muscle pain and history of falls while walking on 3 occasions in the last 2 months. She also gave history of dysphagia and swelling of both the legs since 3 months. There was no history suggestive of sensory or bladder and bowel involvement.

For the swelling of her legs, she was evaluated outside and was concluded as Chronic liver disease with hypoproteinemia and hypothyroidism. Hypothyroidism was treated with thyroid replacement therapy.

On examination, she was well built with normal vitals. She had pallor and bilateral pitting pedal edema. She also had facial puffiness, shiny skin over the face and taut skin over the fingers (sclerodactyly). The other features that she had were restricted mouth opening (up to one and half fingers) and "pepper and salt" skin appearance over both the knees and elbows. 


\section{CASE REPORT}

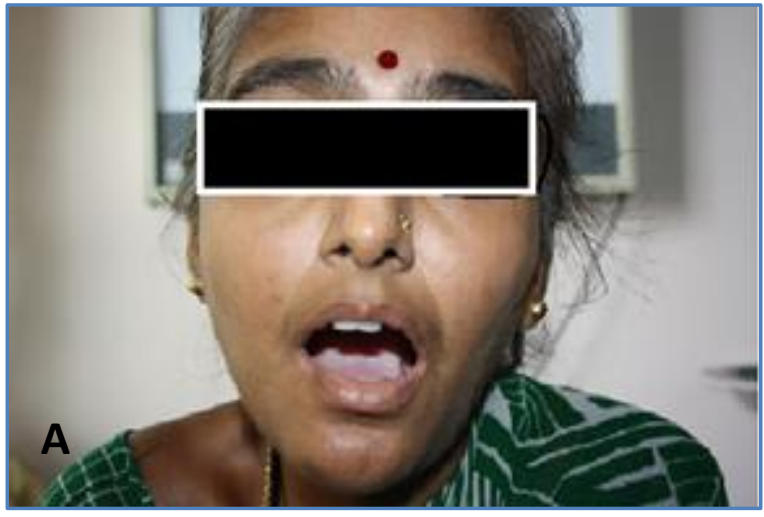

FIG. 1(A): Restricted mouth opening

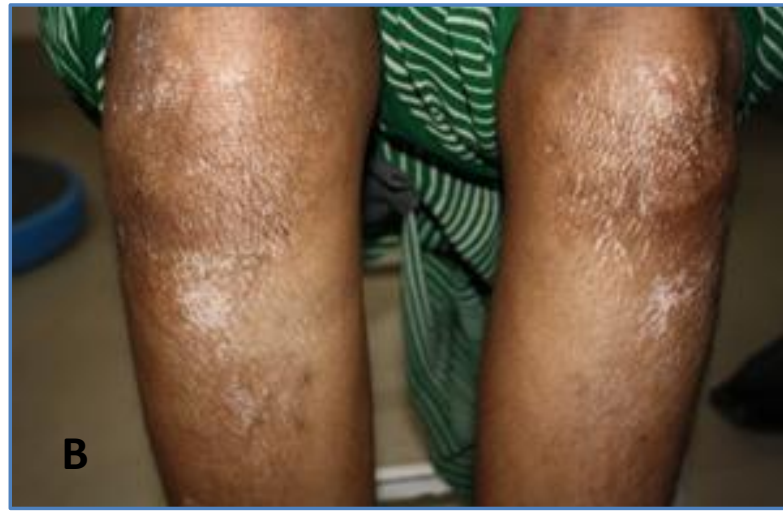

FIG. 1(B): "salt and pepper" appearance of skin at the knees

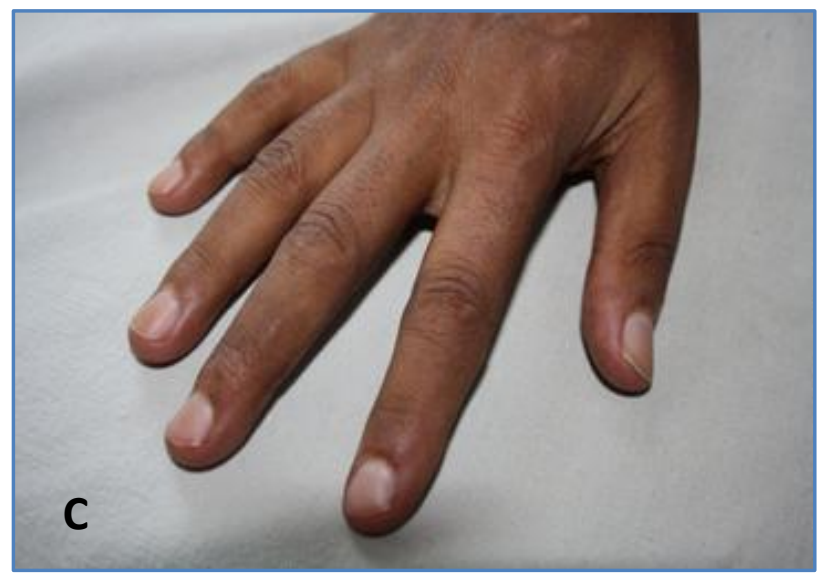

FIG. 1(c): Sclerodactyly

On neurological examination, she had severe muscle tenderness with a power of $3 / 5$ in the proximal and 4/5 in the distal group of muscles. The higher mental functions, tone, reflexes and sensory system were normal. Other systemic examination was essentially unremarkable.

She was admitted for further evaluation with a provisional diagnosis of inflammatory myopathy. On investigating her, she was found to have ESR-100, Creatinine-0.9, SGOT-254, SGPT-240, Albumin- 2.5, Globulin- 5.5, TSH-5.48 and CPK- 3600. In view of the features suggestive of inflammatory myopathy, sclerodactyly, other skin changes, very high ESR and CRP. The patient was further evaluated for autoimmune antibodies to exactly categorize the patient and start treatment.

She was found to have ANA-positive, U1 sn RNP- positive, Anti microsomal-positive Anti scl 70- negative, DNA Topo isomerase- negative, Anti ds DNA- negative, LE cell phenomena-negative, Anti TPO- negative, Anti centromere-negative. Endoscopy showed GERD, Barium swallow was normal and cardiac evaluation was also normal.

Subsequently skin and muscle biopsy was done and sent for histopathological examination. The following images show that the skin biopsy was suggestive of Scleroderma whereas the biceps 
muscle biopsy was suggestive of Dermatomyositis. The patient was diagnosed as "Overlap syndrome - Scleroderma (LcSS) / Myositis (Dermatomyositis).

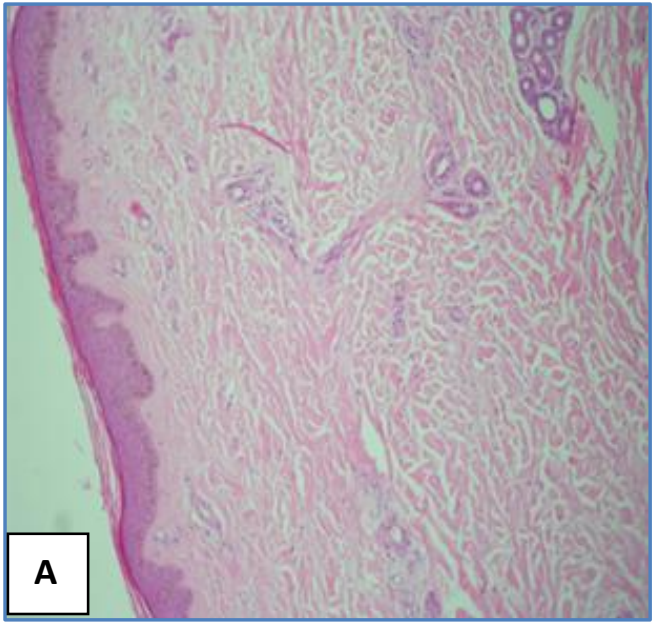

FIG. 2(a)

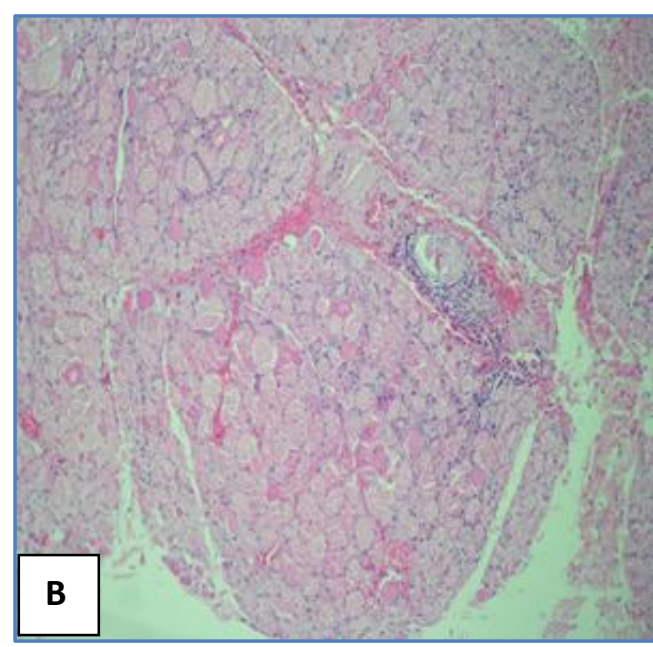

FIG. 2(b)

FIG. 2A: This section shows structure of skin with dermis and epidermis. There is thinning of epidermis. Dermis shows homogenization of collagen and there is pulling up of adenexal structures and subcutaneous fat into mid dermis- features suggestive of Scleroderma.

Fig. 2B: Transverse section of muscle fibres shows perifascicular fibre atrophy. Scattered regenerative fibres are noted within the fascicle with focal infarct like areas are also seen. No necrosis is observed. Chronic inflammatory infiltrate is noted in the interstitium which is perivascularfeatures suggestive of Dermatomyositis.

DISCUSSION: An overlap can be defined when inflammatory myopathy is present in the setting of a connective tissue disease such as Scleroderma, SLE, Sjogren's syndrome, MCTD or Rheumatoid Arthritis. ${ }^{7}$ Rarely, a necrotizing myopathy can be associated with MCTD revealing muscle necrosis. The American College of Rheumatology (ACR) has used classification criteria to assist in categorization and diagnosis of patients with rheumatic diseases.

These classification criteria do not substitute for unique identification of etiologic, clinical or immuno-pathologic features for systemic rheumatic diseases, which are not yet known for most of these disorders. The following disorders are considered to be "undifferentiated" rheumatic diseases and/or "overlap syndromes".

a. Mixed connective tissue disease

- Lupus-scleroderma-polymyositis-rheumatoid arthritis

b. Undifferentiated systemic rheumatic disease

c. Non-classic systemic rheumatic disease

d. Overlap syndromes

- Rheumatoid arthritis-lupus

- Scleroderma-polymyositis/dermatomyositis

- Scleroderma-lupus

- Scleroderma-rheumatoid arthritis 
- Polymyositis overlaps

- Juvenile idiopathic arthritis-lupus

- Sjögren's syndrome overlaps

e. Others

- Undifferentiated polyarthritis syndrome

- Undifferentiated spondyloarthritis

Patients presenting without an obvious diagnosis need thoughtful evaluation and examination with attention to the diagnostic entities listed above. Studies that should be done depend upon the presenting clinical features. These might include antinuclear antibodies, antidsDNA, -Sm, -RNP, -centromere, -Ro/SSA, -La/SSB, -Jo-1, -Scl-70, and -PM1 antibodies, rheumatoid factors, anti-CCP antibodies, erythrocyte sedimentation rate, and nail fold capillaroscopy.

CONCLUSION: Overlap syndromes occur frequently in case of rheumatic diseases so whenever a patient does not fit into one specific condition, extensive work up including autoimmune and histopathological investigations should be undertaken and then tried to ascertain if they fit into any of the overlap syndromes described in the literature. A specific diagnosis should be made only when patients fulfill appropriate classification criteria; these patients should be managed appropriately for that diagnosis. Other patients should be followed, reassessed periodically and managed according to their major rheumatologic symptom(s).

\section{REFERENCES:}

1. Tager RE, Tikly M: Clinical and laboratory manifestations of systemic sclerosis (scleroderma) in Black South Africans. Rheumatology (Oxford) 1999, 38.

2. Cervera R, Khamashta MA, Hughes GR. 'Overlap' syndromes. Ann Rheum Dis 1990; 49:947.

3. Dubois, EL, Wallace, DJ. Differential diagnosis. In: Dubois' Lupus Erythematosus, Wallace, DJ, Dubois EL (Eds), Lea \& Febiger, Philadelphia, 1987, p. 470.

4. LeRoy EC, Maricq HR, Kahaleh MB. Undifferentiated connective tissue syndromes. Arthritis Rheum 1980; 23:341.

5. Doria A, Mosca M, Gambari PF, Bombardieri S. Defining unclassifiable connective tissue diseases: incomplete, undifferentiated, or both? J Rheumatol 2005; 32:213.

6. Greer JM, Panush RS. Incomplete lupus erythematosus. Arch Intern Med 1989; 149:2473.

7. Harrison's principles of internal medicine, $18^{\text {th }}$ edition, page 3511 . 


\section{CASE REPORT}

\section{AUTHORS:}

1. Diwakar K. Singh

2. Nataraju H. V

\section{PARTICULARS OF CONTRIBUTORS:}

1. Post Graduate, Department of General Medicine, Kempegowda Institute of Medical Sciences, Bangalore.

2. Professor and HOD, Department of Medicine, KIMS, Bangalore

\section{NAME ADDRESS EMAIL ID OF THE}

\section{CORRESPONDING AUTHOR:}

Dr. Diwakar K. Singh,

KIMS Resident Quarters,

Room No. 208,

KIMS Hospital,

V. V. Puram, Bangalore - 560004.

Email: divaaaka@gmail.com

Date of Submission: 17/05/2014.

Date of Peer Review: 19/05/2014.

Date of Acceptance: 26/05/2014.

Date of Publishing: 03/06/2014. 